\title{
Fixed-Time Stability of the Hydraulic Turbine Governing System
}

\author{
Caoyuan Ma, ${ }^{1}$ Chuangzhen Liu $\mathbb{D},{ }^{1}$ Xuezi Zhang, ${ }^{1}$ Yongzheng Sun $\mathbb{D}{ }^{2}$ \\ Wenbei Wu $\mathbb{D}^{1}{ }^{1}$ and Jin Xie ${ }^{1}$ \\ ${ }^{1}$ School of Electrical and Power Engineering, China University of Mining and Technology, Xuzhou 221116, China \\ ${ }^{2}$ School of Mathematics, China University of Mining and Technology, Xuzhou 221008, China \\ Correspondence should be addressed to Yongzheng Sun; yzsun@cumt.edu.cn
}

Received 11 August 2017; Revised 16 December 2017; Accepted 21 December 2017; Published 30 January 2018

Academic Editor: Ton D. Do

Copyright (C) 2018 Caoyuan Ma et al. This is an open access article distributed under the Creative Commons Attribution License, which permits unrestricted use, distribution, and reproduction in any medium, provided the original work is properly cited.

\begin{abstract}
This paper studies the problem of fixed-time stability of hydraulic turbine governing system with the elastic water hammer nonlinear model. To control and improve the quality of hydraulic turbine governing system, a new fixed-time control strategy is proposed, which can stabilize the water turbine governing system within a fixed time. Compared with the finite-time control strategy where the convergence rate depends on the initial state, the settling time of the fixed-time control scheme can be adjusted to the required value regardless of the initial conditions. Finally, we numerically show that the fixed-time control is more effective than and superior to the finite-time control.
\end{abstract}

\section{Introduction}

Hydropower, as a low-cost, zero-polluting, and renewable energy source, has been deeply developed since the twentieth century [1]. With the reserves of coal, natural gas, and other nonrenewable energy sources decreasing gradually and the serious environmental problems caused by power generation, hydropower is becoming an increasingly large proportion of the electricity structure. According to the current projections provided by international hydropower industries referring to the next thirty years, a significant growth in the sector is expected [2]. As a typical nonlinear complex system and an important part of hydraulic power generation system, hydraulic turbine governing system is a hydraulic, mechanical, electrical integrated control system [3]. The normal operation of the water turbine governing system is essential to the whole hydraulic power system, and it even affects the safe and stable operation of the related power grid, thus affecting the power quality and the power consumption experience of the users. In view of the high proportion of the hydropower system in the electricity structure, the research of the hydraulic turbine governing system is of great importance.

At present, the control method commonly used in water turbine control system mainly includes the following: nonlinear control [4-7], sliding mode control [8-10], PID control [11-13], fuzzy control [14], fault tolerant control [15], predictive control $[16,17]$, and finite-time control [18]. These control methods have important theoretical and practical significance for the control of hydraulic turbine governing system, but they also have their own defects. For example, feedback control has the time delay problem. The nonlinear control is targeted, and each nonlinear control strategy is only suitable for solving some special nonlinear system control problems. PID control is difficult to balance the stability time and overshoot. When the initial state of the system deviates from the equilibrium point, it is difficult for the control system to restore the system to the equilibrium point; fuzzy control is difficult to adapt to the requirements of large-scale adjustment, and it needs to constantly adjust the control rules and parameters. The effect of fault tolerant control is greatly influenced by the delay of fault detection and separation, and the long time delay will cause serious stability problem. Predictive control's accuracy is not very high, and the optimization process needs to be performed online repeatedly; in finite-time control, the stability of the system is affected by the initial state of the system. All the above control strategies can ensure the exponential stability of the system, while the adjustment time affected by the initial state of the system is not always short enough. The 
fixed-time stability control not only ensures the exponential stability and the shorter adjustment time but also has stronger robustness and disturbance rejection ability than the above control strategies.

The definition of the fixed-time stability was firstly proposed by Polyakov in [19], and this definition was evolved from the definition of finite-time stability. Finite-time control theory has been widely used in Cucker-Smale systems [20], complex dynamic network systems [21], PMSM [22], delay neural networks systems [23], chaotic systems [24], and so forth. Compared with the finite-time control, the fixed-time control has the characteristic that the maximum adjustment time is not affected by the initial conditions. In view of many advantages of fixed-time control, the control method has been widely used in multiagent systems [25], aircraft systems [26], robot systems [27], neural network systems [28-31], and chaotic systems $[32,33]$.

In [16], a six-dimensional nonlinear mathematical model for the elastic water hammer of hydraulic turbine governing system is presented. Based on the six-dimensional nonlinear mathematical model, this paper analyzes the system running state without controllers. Comparing the operation status of the system under the fixed-time control strategy and the finite-time control strategy, we find that the control strategy used in this paper can directly calculate the system's settling time. The settling time is independent of the initial state of the system. In conclusion, whether the initial state of the system changes or not, we can use the fixed-time control strategy to make the system achieve stable state quickly.

\section{Fixed-Time Stability of Hydraulic Turbine Governing System}

2.1. System Modeling and Preliminaries. For the convenience of analysis, we give some necessary definitions and lemmas in advance.

Definition 1 (see [19]). Consider the following nonlinear dynamic system:

$$
\dot{x}=f(x),
$$

where $x \in R^{n}$ is the system state, $f$ is a smooth nonlinear function. If, for any initial condition, there exists a fixed settling time $T_{0}$, which is not connected with initial condition, such that

$$
\lim _{t \rightarrow T_{0}}\|x(t)\|=0
$$

and $\|x(t)\| \equiv 0$, if $t \geq T_{0}$, then this nonlinear dynamic system is said to be fixed-time stable.

Lemma 2 (see [34]). Suppose there exists a continuous function such that $V(t):[0, \infty) \rightarrow[0, \infty)$ such that

(1) $V$ is positive definite,

(2) there exist real numbers $c>0$ and $0<\rho<1$, such that

$$
\dot{V}(t) \leq-c V^{\rho}(t), \quad t \geq t_{0}
$$

and then one has

$$
\begin{aligned}
V^{1-\rho}(t) & \leq V^{1-\rho}\left(t_{0}\right)-c(1-\rho)\left(t-t_{0}\right), \quad t_{0} \leq t \leq t^{*}, \\
V(t) & =0, \quad t \geq t^{*},
\end{aligned}
$$

of which

$$
t^{*}=t_{0}+\frac{V^{1-\rho}\left(t_{0}\right)}{c(1-\rho)} .
$$

Lemma 3 (see [19]). If there exists a continuous radically unbounded function $V: R^{n} \rightarrow R_{+} \cup|0|$, such that

(1) $V(x)=0 \Leftrightarrow x=0$,

(2) any solution $x(t)$ satisfied the inequality $D^{*} V(x(t)) \leq$ $-\alpha V^{p}(x(t))-\beta V^{q}(x(t))$ for some $\alpha, \beta$, and $p=1-$ $1 / 2 \gamma, q=1+1 / 2 \gamma$, and $\gamma>1$, where $D^{*} V(x(t))$ denotes the upper right-hand derivative of the function $V(x(t))$,

Then the origin is globally fixed-time stable and the following estimate holds:

$$
T\left(x_{0}\right) \leq T_{\max }:=\frac{\pi \gamma}{\sqrt{\alpha \beta}}, \quad \forall x_{0} \in R^{N} .
$$

Lemma 4 (see [35]). If $x_{1}, x_{2}, \ldots, x_{N} \geq 0$, then

$$
\begin{aligned}
& \sum_{i=1}^{N} x_{i}^{\eta} \geq\left(\sum_{i=1}^{N} x_{i}\right)^{\eta}, \quad 0<\eta \leq 1, \\
& \sum_{i=1}^{N} x_{i}^{\theta} \geq N^{1-\theta}\left(\sum_{i=1}^{N} x_{i}\right)^{\theta}, \quad \theta>1 .
\end{aligned}
$$

2.2. Main Results. Here, we use the nonlinear model of the water turbine strike system proposed in [18]:

$$
\begin{aligned}
\dot{x}_{1} & =x_{2} \\
\dot{x}_{2} & =x_{3} \\
\dot{x}_{3} & =-a_{0} x_{1}-a_{1} x_{2}-a_{2} x_{3}+y \\
\dot{\delta} & =\omega_{0} \omega \\
\dot{\omega} & =\frac{1}{T_{a b}}\left[m_{t}-D \omega-P_{e}\right] \\
\dot{y} & =-\frac{y}{T_{y}},
\end{aligned}
$$

where

$$
\begin{aligned}
P_{e}= & \frac{E_{q}^{\prime} V_{s}}{x_{d \Sigma}^{\prime}} \sin \delta+\frac{V_{s}^{2}}{2} \frac{x_{d \Sigma}^{\prime}-x_{q \Sigma}}{x_{d \Sigma}^{\prime} x_{q \Sigma}} \sin 2 \delta \\
m_{t}= & b_{3} y+\left(b_{0}-a_{0} b_{3}\right) x_{1}+\left(b_{1}-a_{1} b_{3}\right) x_{2} \\
& +\left(b_{2}-a_{2} b_{3}\right) x_{3}
\end{aligned}
$$




$$
\begin{aligned}
x_{d \Sigma}^{\prime} & =x_{d}^{\prime}+x_{T}+\frac{1}{2} x_{L} \\
x_{q \Sigma} & =x_{q}+x_{T}+\frac{1}{2} x_{L} \\
b_{0} & =\frac{24 e_{y}}{e_{q h} h_{\omega} T_{r}^{3}}, \\
b_{1} & =-\frac{24 e e_{y}}{e_{q h} T_{r}^{2}}, \\
b_{2} & =\frac{3 e_{y}}{e_{q h} h_{\omega} T_{r}}, \\
b_{3} & =-\frac{e e_{y}}{e_{q h}}, \\
a_{0} & =\frac{24}{e_{q h} h_{\omega} T_{r}^{3}}, \\
a_{1} & =\frac{24}{T_{r}^{2}}, \\
a_{2} & =\frac{3}{e_{q h} h_{\omega} T_{r}} .
\end{aligned}
$$

$x_{1}, x_{2}$, and $x_{3}$ are state variables; $\delta$ is the generator rotor angle, $\omega$ is the relative value of generator speed, $y$ is the incremental deviation of the guide vane opening, $D$ is generator damping coefficient, $e$ is intermediate variable, $e_{q h}$ is the first-order partial derivative value of flow rate with respect to water head, $e_{y}$ is the first-order partial derivative value of torque with respect to wicket gate, $E_{q}^{\prime}$ is the transient internal voltage of the armature, $h_{\omega}$ is characteristic coefficient of water diversion system, $m_{t}$ is torque relative value of hydraulic turbine, $T_{y}$ is relay reaction time constant, $x_{d}^{\prime}$ is the direct axis transient reactance, $x_{q}$ is the quartered axis reactance, $x_{T}$ is the short circuit reactance of the transformer, $x_{L}$ is the reactance of the electric transmission line, and $V_{s}$ is the bus voltage at infinity.

From system (8), we can see that $P(0,0,0, m, 0,0)$ is a point of equilibrium of the system, where $m$ is a constant. In order to make the system fast and stable to the equilibrium point $P$, the fifth and sixth subsystems of model (8) are added with the controllers $u_{\omega}$ and $u_{y}$, and the controlled system is formed as follows:

$$
\begin{aligned}
\dot{x}_{1} & =x_{2} \\
\dot{x}_{2} & =x_{3} \\
\dot{x}_{3} & =-a_{0} x_{1}-a_{1} x_{2}-a_{2} x_{3}+y \\
\dot{\delta} & =\omega_{0} \omega \\
\dot{\omega} & =\frac{1}{T_{a b}}\left[m_{t}-D \omega-P_{e}\right]+u_{\omega} \\
\dot{y} & =\frac{1}{T_{y}}\left(-y+u_{y}\right) .
\end{aligned}
$$

Theorem 5. The hydraulic turbine governing system (10) can become stable in a fixed time, under the following controllers:

$$
\begin{aligned}
u_{y}= & -k_{1} \operatorname{sign}(y)|y|^{\alpha}-k_{1} \operatorname{sign}(y)|y|^{\beta} \\
u_{\omega}= & -\frac{m_{t}-P_{e}-b_{3} \cdot y}{T_{a b}}-k_{2} \operatorname{sign}(\omega)|\omega|^{\alpha} \\
& -k_{2} \operatorname{sign}(\omega)|\omega|^{\beta},
\end{aligned}
$$

where the parameters $\alpha$ and $\beta$ satisfy $0<\alpha<1$ and $\beta>1$ and the parameters $k_{1}$ and $k_{2}$ are tuning parameters of the terminal attractor.

Proof. Here, we use the two-step method of two steps to prove that the system is stable for the fixed time; for the sixth subsystem of system (10), we put $u_{y}$ into the controlled subsystem, and we can have the following relationship:

$$
\frac{d y}{d t}=\frac{1}{T_{y}}\left(-y-k_{1} \operatorname{sign}(y)|y|^{\alpha}-k_{1} \operatorname{sign}(y)|y|^{\beta}\right) .
$$

The Lyapunov function is constructed as follows:

$$
V_{1}(t)=\frac{y^{2}}{2} .
$$

The derivative along the trajectory of the sixth subsystem in (10) can be obtained:

$$
\begin{aligned}
& \frac{d V_{1}(t)}{d t}=y \frac{d y}{d t}=\frac{y}{T_{y}}\left[-y-k_{1} \operatorname{sign}(y)|y|^{\alpha}\right. \\
& \left.-k_{1} \operatorname{sign}(y)|y|^{\beta}\right]=-\frac{1}{T_{y}}\left(y^{2}+k_{1}|y|^{\alpha+1}\right. \\
& \left.+k_{1}|y|^{\beta+1}\right) \leq-\frac{k_{1}}{T_{y}}\left[\left(y^{2}\right)^{(\alpha+1) / 2}+\left(y^{2}\right)^{(\beta+1) / 2}\right] \\
& =-\frac{k_{1}}{T_{y}}\left[\left(\frac{y^{2}}{2}\right)^{(\alpha+1) / 2} \cdot\left(\frac{1}{2}\right)^{-(\alpha+1) / 2}+\left(\frac{y^{2}}{2}\right)^{(\beta+1) / 2}\right. \\
& \left.\cdot\left(\frac{1}{2}\right)^{-(\beta+1) / 2}\right]=-\frac{k_{1}}{T_{y}} \cdot 2^{(\alpha+1) / 2} V_{1}^{(\alpha+1) / 2}(t)-\frac{k_{1}}{T_{y}} \\
& \cdot 2^{(\beta+1) / 2} V_{1}^{(\beta+1) / 2}(t),
\end{aligned}
$$

where

$$
\begin{aligned}
& m=\frac{k_{1}}{T_{y}} \cdot 2^{(\alpha+1) / 2}, \\
& n=\frac{k_{1}}{T_{y}} \cdot 2^{(\beta+1) / 2}, \\
& p=\frac{\alpha+1}{2}, \\
& q=\frac{\beta+1}{2} .
\end{aligned}
$$


According to Lemma 3, we know that the sixth subsystem in model (10) is stable in fixed time:

$$
t_{1}=\frac{\pi T_{y}}{k_{1}(\beta-\alpha) \cdot 2^{(\alpha+\beta-2) / 4}}
$$

which means that the system state variable $y$ satisfies the following relation $y=0$ when $t \geq t_{1}$. And

$$
\begin{aligned}
\dot{x}_{1} & =x_{2} \\
\dot{x}_{2} & =x_{3} \\
\dot{x}_{3} & =-a_{0} x_{1}-a_{1} x_{2}-a_{2} x_{3} \\
\dot{\delta} & =\omega_{0} \omega \\
\dot{\omega} & =\frac{1}{T_{a b}}\left[\left(b_{0}-a_{0} b_{3}\right) x_{1}+\left(b_{1}-a_{1} b_{3}\right) x_{2}\right. \\
& \left.+\left(b_{2}-a_{2} b_{3}\right) x_{3}-D \omega-P_{e}\right]+u_{\omega} .
\end{aligned}
$$

To this end, we select the following Lyapunov function:

$$
V_{2}(t)=\frac{\omega^{2}}{2}
$$

Thus,

$$
\begin{aligned}
& \frac{d V_{2}(t)}{d t}=\omega \frac{d \omega}{d t}=\omega\left[-\frac{D \omega}{T_{a b}}-k_{2} \operatorname{sign}(\omega)|\omega|^{\alpha}\right. \\
& \left.-k_{2} \operatorname{sign}(\omega)|\omega|^{\beta}\right]=-\frac{D \omega^{2}}{T_{a b}}-k_{2}|\omega|^{\alpha+1} \\
& -k_{2}|\omega|^{\beta+1} \leq-k_{2}|\omega|^{\alpha+1}-k_{2}|\omega|^{\beta+1} \\
& =-k_{2}\left[2^{(\alpha+1) / 2} \cdot\left(\frac{\omega^{2}}{2}\right)^{(\alpha+1) / 2}+2^{(\beta+1) / 2}\right. \\
& \left.\cdot\left(\frac{\omega^{2}}{2}\right)^{(\beta+1) / 2}\right]=-k_{2} \cdot 2^{(\alpha+1) / 2} V_{2}^{(\alpha+1) / 2}(t)-k_{2} \\
& \cdot 2^{(\beta+1) / 2} V_{2}^{(\beta+1) / 2}(t),
\end{aligned}
$$

where

$$
\begin{aligned}
& m=k_{2} \cdot 2^{(\alpha+1) / 2}, \\
& n=k_{2} \cdot 2^{(\beta+1) / 2}, \\
& p=\frac{\alpha+1}{2} \\
& q=\frac{\beta+1}{2} .
\end{aligned}
$$

According to Lemma 3, we can show that the fourth and fifth subsystems in model (10) are stable in fixed time:

$$
t_{2}=\frac{\pi}{k_{2}(\beta-\alpha) \cdot 2^{(\alpha+\beta-2) / 4}}
$$

which means that when $t \geq t_{2}$, then $\omega=0$ and $\dot{\delta}=0$. In other words, when $t \geq t_{1}+t_{2}$, the value of $\delta$ tends to be stable.

To sum up, when $t \geq t_{3}$, where $t_{3}=t_{1}+t_{2}+\Delta t$ and $\Delta t$ is the time from $y=0$ to $u_{\omega}$ acting on model (10), the hydraulic turbine governing system (10) is stable under the controllers $u_{y}$ and $u_{\omega}$. That is, the system is stable in a fixed time, and the theorem is proved.

\section{Numerical Simulations}

In this section, numerical results are provided to verify the theoretical results. The system parameters and controller parameters in this paper are $\omega_{0}=314, T_{a b}=8.0, D=0.5$, $E_{q}^{\prime}=1.35, x_{d \Sigma}^{\prime}=1.15, x_{q \Sigma}=1.474, T_{y}=0.1, V_{s}=1.0$, $e_{q h}=0.5, e_{y}=1.0, T_{r}=1.0, h_{\omega}=2.0, r=0, a_{0}=24, a_{1}=24$, $a_{2}=3, b_{0}=24, b_{1}=33.6, b_{2}=3$, and $b_{3}=-1.4$, respectively. The simulation sampling time is $0.0001 \mathrm{~s}$, and the initial states are $\left(x_{1}, x_{2}, x_{3}, \delta, \omega, y\right)=(0.1,0.1,0.1,0.1,0.1,0.1)$.

Figures $1(\mathrm{a})-1(\mathrm{c})$ are the response curves of the system variables $\delta, \omega$, and $y$ when the hydraulic turbine governing system is not controlled. From Figure 1, it is clear that the steady state of the system state variable $y$ is about $0.6 \mathrm{~s}$ before being controlled. The state of the system variables $\delta$ and $\omega$ are aperiodic and are always in a state of instability.

Figures 2(a)-2(b) are the response curves of the fixedtime controllers $u_{\omega}$ and $u_{y}$, respectively. In this simulation, $u_{y}$ acts on the hydraulic turbine governing system in $0.3 \mathrm{~s}$, and $u_{\omega}$ acts on the hydraulic turbine governing system in $0.75 \mathrm{~s}$. Figures $3(\mathrm{a})-3(\mathrm{c})$ are the response curves of the system variables $\delta, \omega$, and $y$ after the fixed-time controllers $u_{y}$ and $u_{\omega}$ are applied to the hydraulic turbine governing system, respectively. From Figure 3, it is clear that when the system is coupled with $u_{y}$ in $0.3 \mathrm{~s}$ and $u_{\omega}$ in $0.75 \mathrm{~s}$, the system state variable $y$ reaches a stable state at $0.326 \mathrm{~s}$, and the system state variables $\delta$ and $\omega$ achieve stable state at $2 \mathrm{~s}$, simultaneously. The simulation results show that the system can achieve a stable state in a short time by fixed-time controllers, and the control effect is achieved.

In order to make a fair comparison between fixedtime control and finite-time control, the parameters, initial conditions, and the tuning parameters of the terminal attractor are the same in this paper. Figures 4(a)-4(c) are the comparison of response curves of system state variables $\delta, \omega$, and $y$ with fixed-time controllers and finite-time controllers, respectively. From Figure 4, it is obvious that the settling time of system state variable $y$ under the action of fixed-time controllers is mostly equal to the settling time of system state variable $y$ under the action of the finite-time controllers. The system state variables $\delta$ and $\omega$ achieve stable state at $2 \mathrm{~s}$ under the action of fixed-time controllers, simultaneously. And the system state variables $\delta$ and $\omega$ achieve stable state at $2.07 \mathrm{~s}$ under the action of finite-time controllers, simultaneously. The fixed-time controllers stabilize the nonlinear system faster than finite-time controllers do. Thus, the fixed-time method has the better capacity to handle a nonlinear system in a short time.

To explore the relationship between the settling time and the values of the parameters $\alpha$ and $\beta$ experimentally, we 


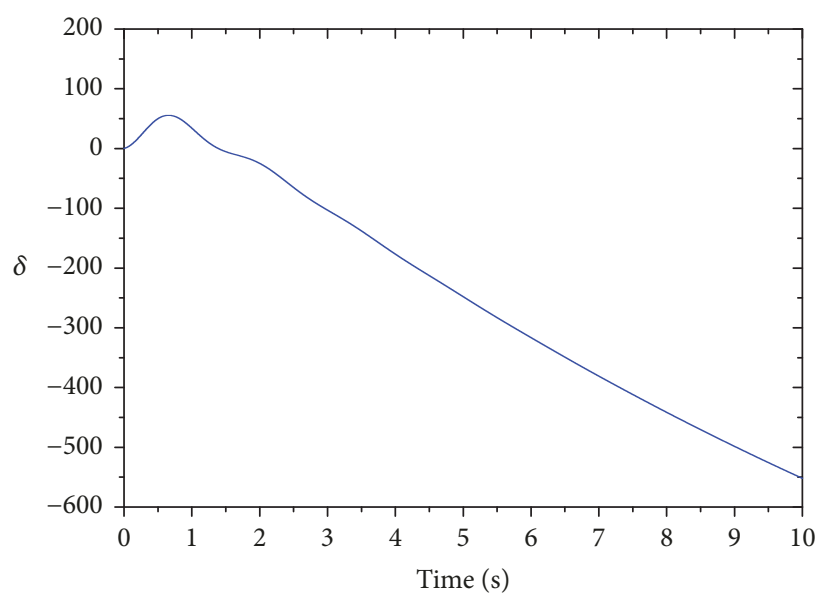

(a)

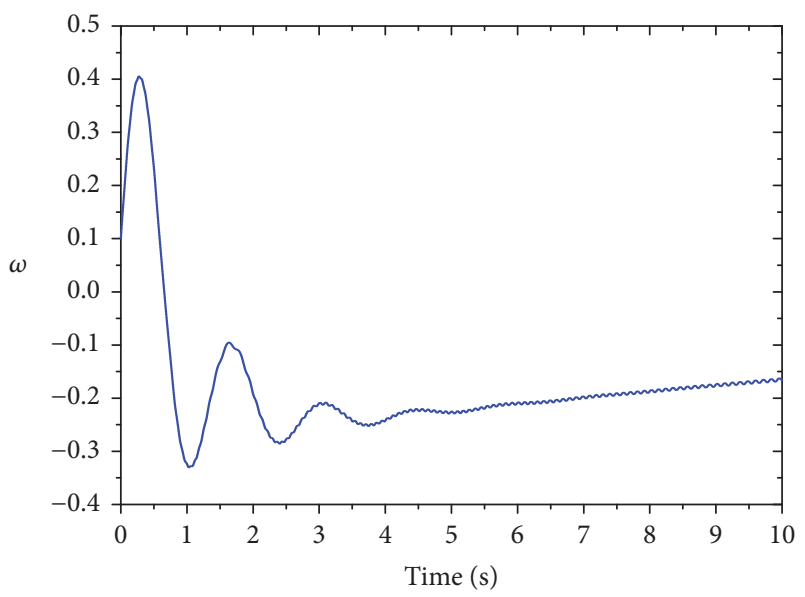

(b)

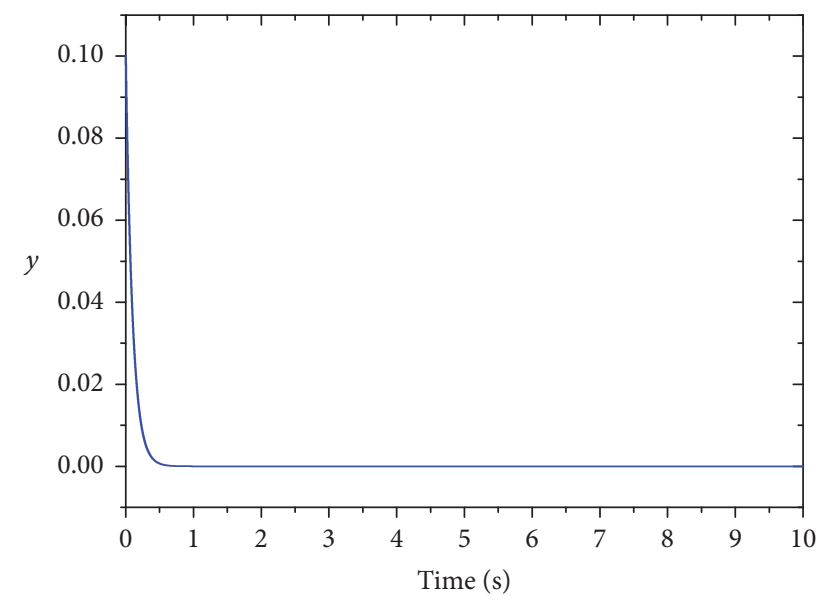

(c)

FIGURE 1: The response of the system without controller.

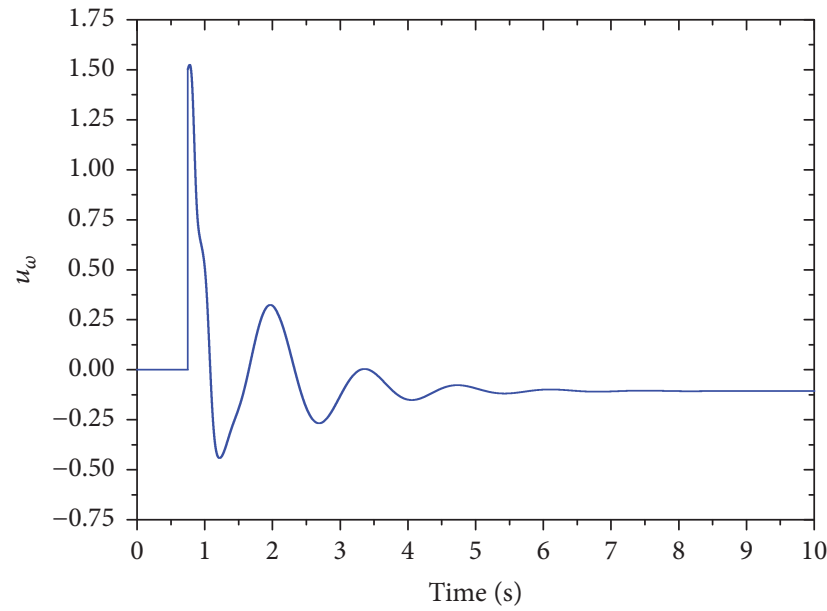

(a)

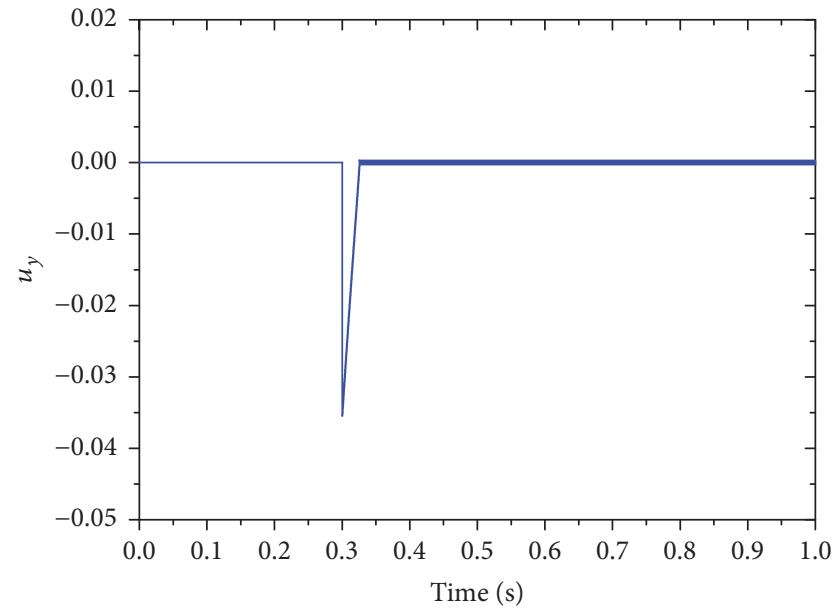

(b)

FIGURE 2: The response of the fixed-time controllers $u_{\omega}$ and $u_{y}$. 


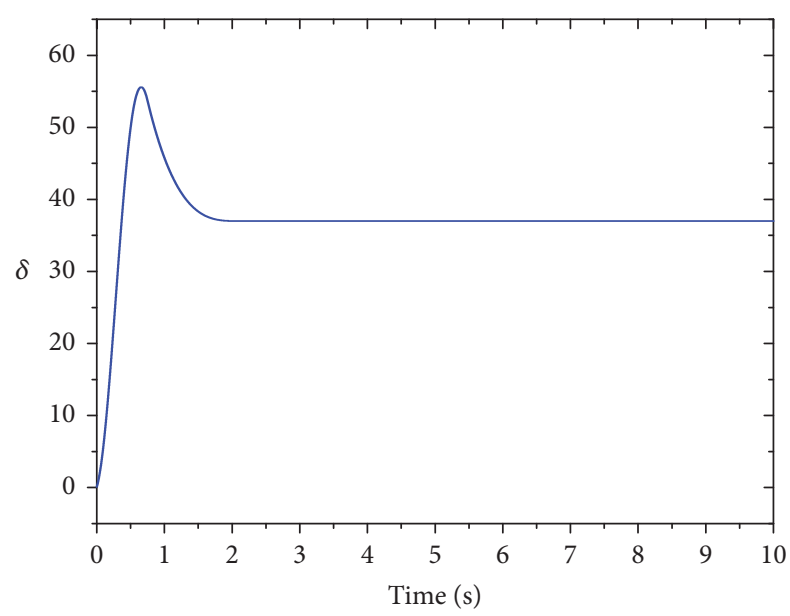

(a)

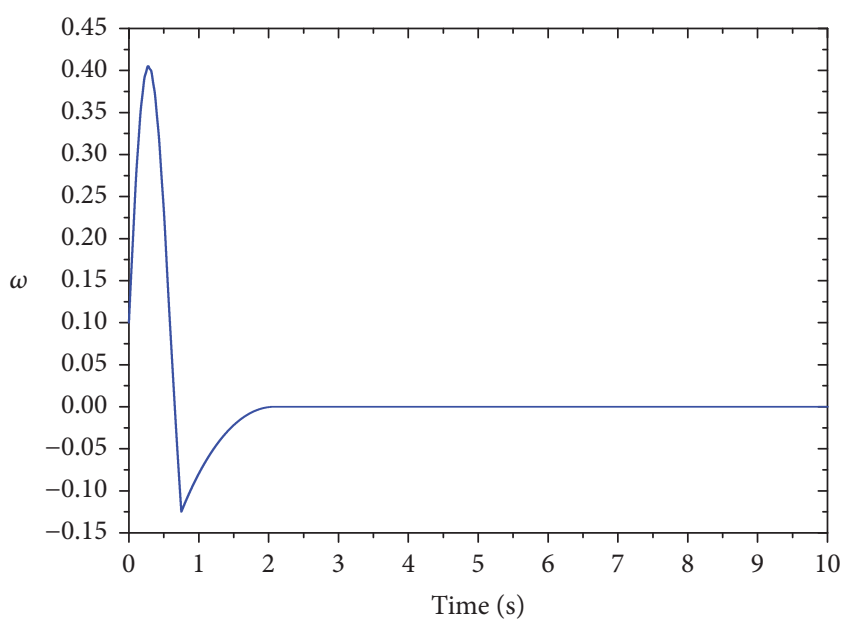

(b)

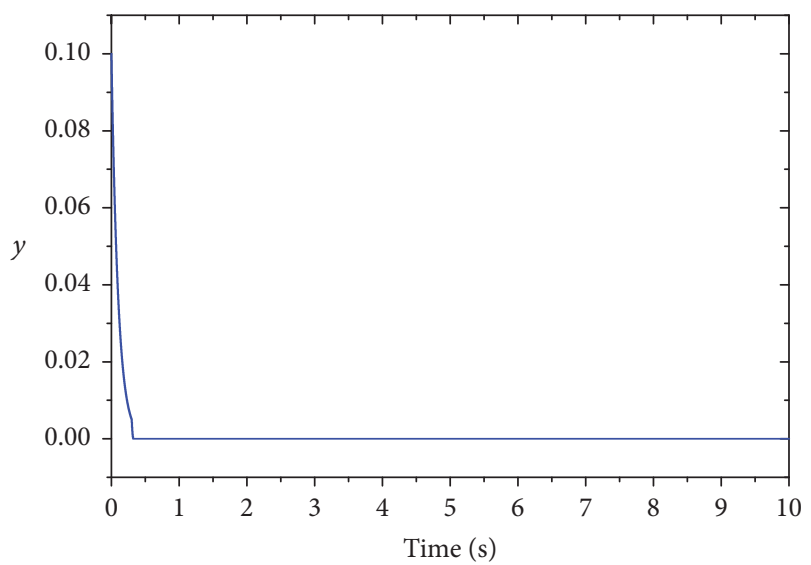

(c)

FIGURE 3: The response of the system with fixed-time controllers.

select system state variables $\delta$, $\omega$, and $y$ to demonstrate the settling time. Figures 5(a)-5(c) and Figures 6(a)-6(c) are, respectively, the effects of different control parameters $\alpha$ and $\beta$ on the state variables $\delta, \omega$, and $y$ under the fixed-time controllers. In Figure 5, the parameter values are $\beta=1.5$ and $\alpha=0.3,0.4,0.5,0.6,0.7$. In Figure 6 , the parameter values

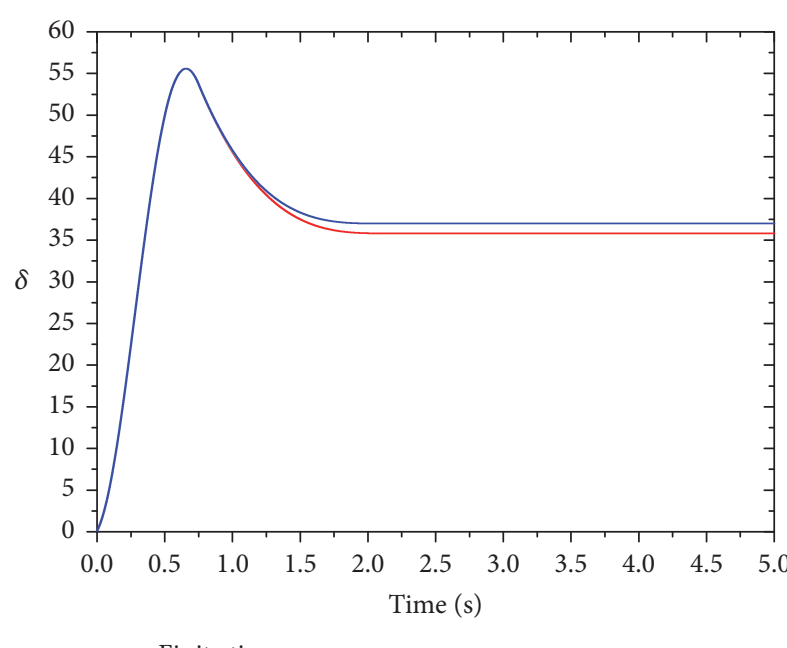

Finite time

- Fixed time

(a)

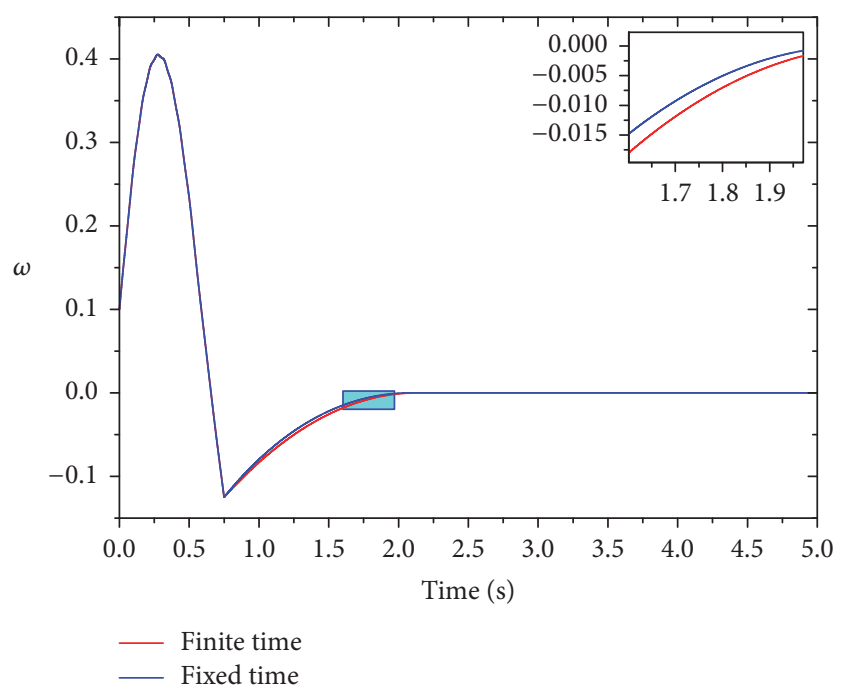

(b)

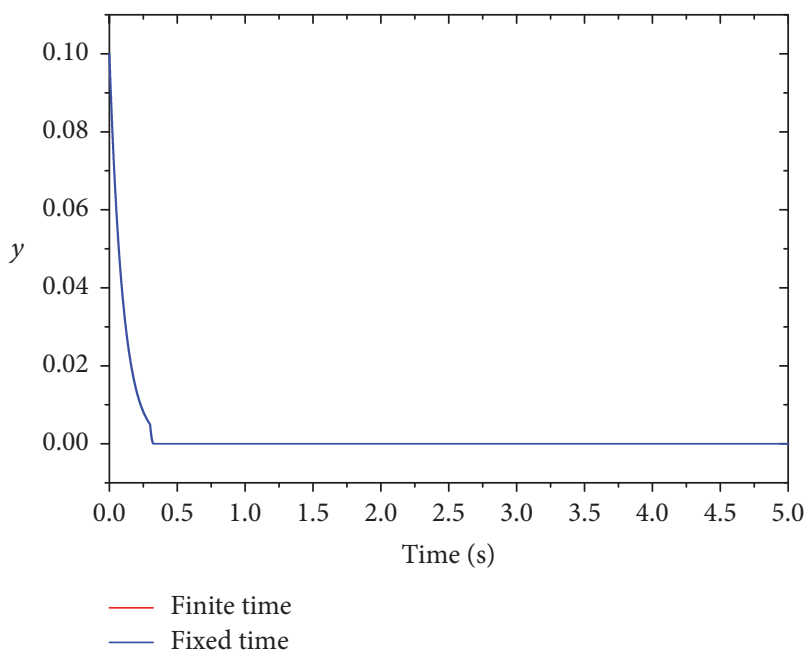

(c)

FIGURE 4: Comparison of converging speed of fixed-time and finitetime controllers. 


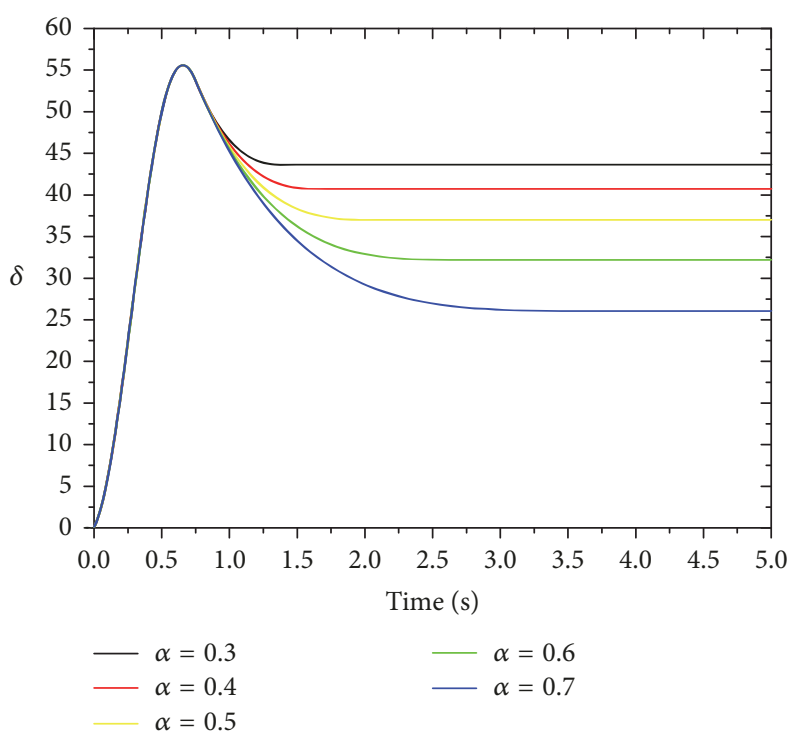

(a)

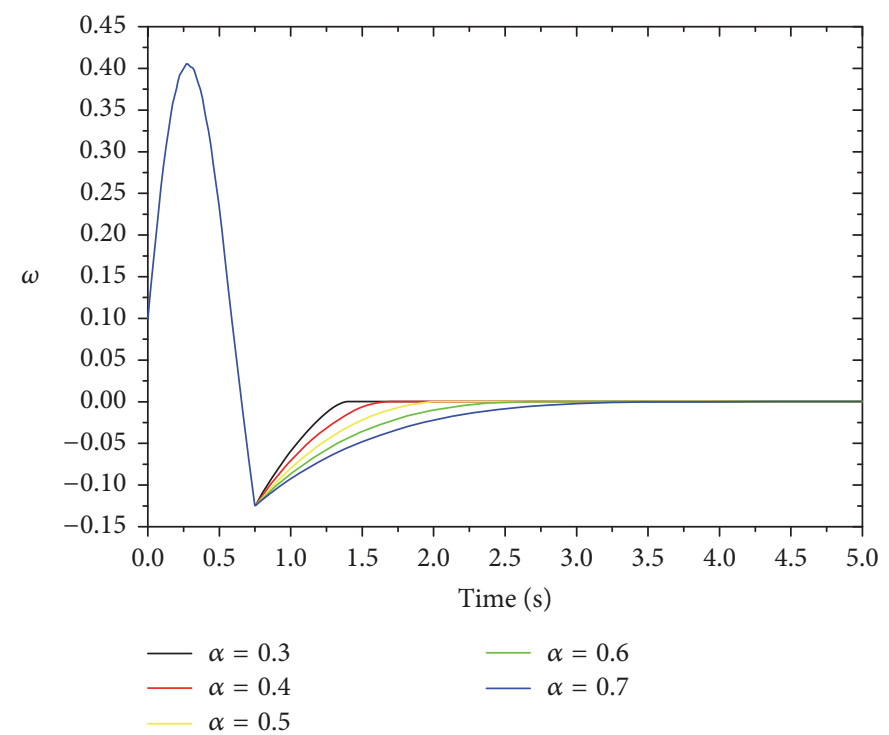

(b)

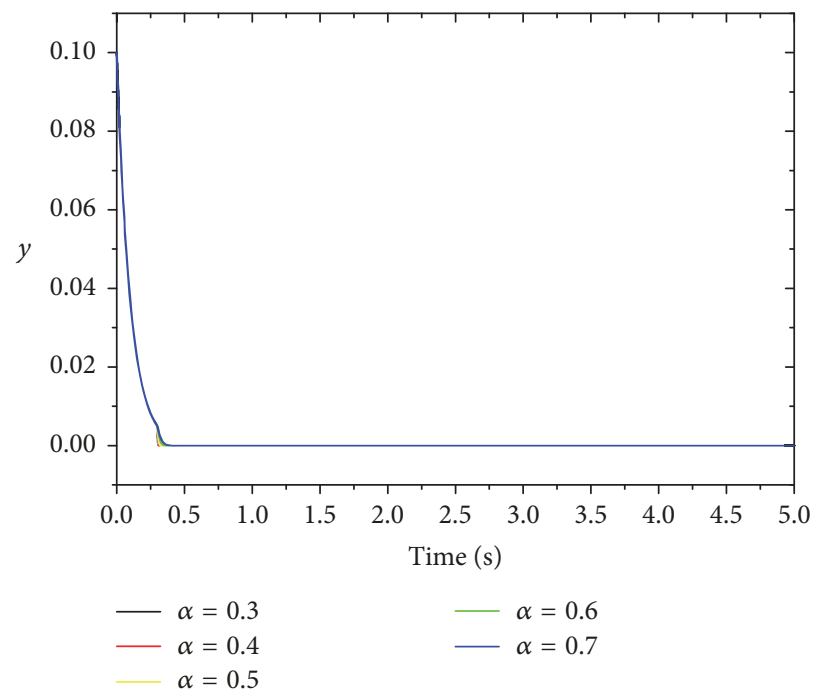

(c)

FIGURE 5: Response of $\alpha$ of the system controlled by fixed-time controllers.

are $\alpha=0.5$ and $\beta=1.1,1.3,1.5,1.7,1.9$. In Figures 5 and 6 , the system parameters and other controller parameters and tuning parameters of the terminal attractor are consistent with the previous sections. The simulation results clearly show that changing the controller parameters $\alpha$ and $\beta$ can change the time of the system state variables $\delta$ and $\omega$ to reach the steady state. But the time of the system state variable $y$ to reach the steady state is almost the same. And the smaller the $\alpha$ and $\beta$ value of the system are, the faster the settling time will be. Moreover, the influence of $\beta$ on the settling time of the system state variables $\delta$ and $\omega$ is less than the influence of $\alpha$ on the settling time of the system state variables $\delta$ and $\omega$. The simulation results are consistent with the theoretical analysis of the maximum stable time $t_{3}$ of the system in the previous section. Moreover, the values of $\alpha$ and $\beta$ also affect the stability value of the system state variable $\delta$. That is to say, we can get the size of the system state variable $\delta$ to the numerical value we need by controlling the size of $\alpha$ and $\beta$.

In order to explore the effect of the initial state of hydropower system with fixed-time controllers, we compared the response of three different initial conditions of the hydropower system. Figures $7(\mathrm{a})-7(\mathrm{c})$ show the response of the system state variables $\delta, \omega$, and $y$ at different initial conditions with the fixed-time controllers $u_{\omega}$ and $u_{y}$, respectively. From Figures $7(\mathrm{a})-7(\mathrm{c})$, it is clear that when the initial states of system are $S 1=$ $(0.08,0.08,0.08,0.08,0.08,0.08), S 2=(0.1,0.1,0.1,0.1,0.1$, $0.1)$, and $S 3=(0.12,0.12,0.12,0.12,0.12,0.12)$ and the system is coupled with $u_{y}$ at $0.3 \mathrm{~s}$ and $u_{\omega}$ at $0.75 \mathrm{~s}$, the system state variables $\delta$ are stable at $1.92 \mathrm{~s}, 2 \mathrm{~s}$, and $2.22 \mathrm{~s}$, respectively. The system states variables $\omega$ are also stable at $1.92 \mathrm{~s}, 2 \mathrm{~s}$, and $2.22 \mathrm{~s}$, respectively. The system state variables $y$ are all stable 


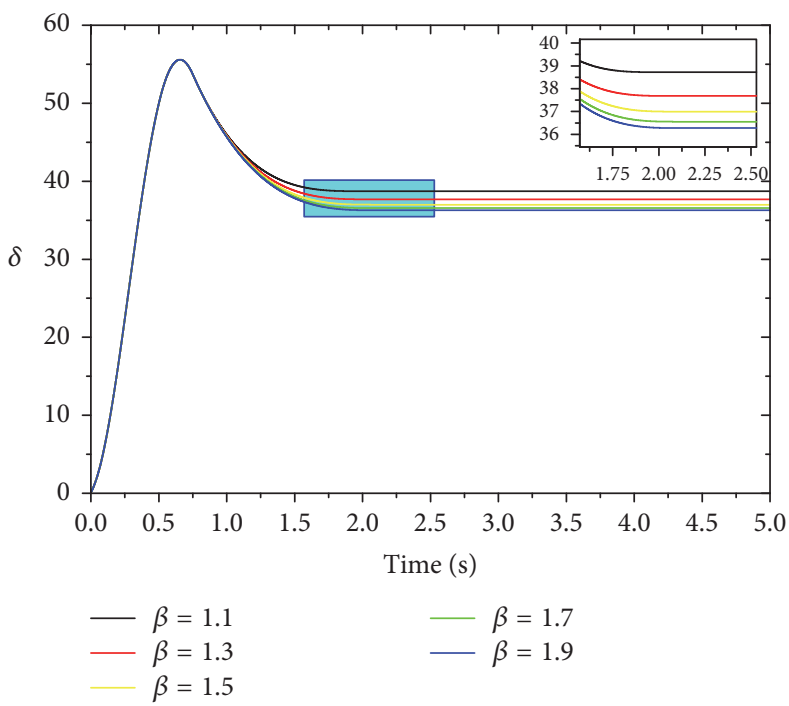

(a)

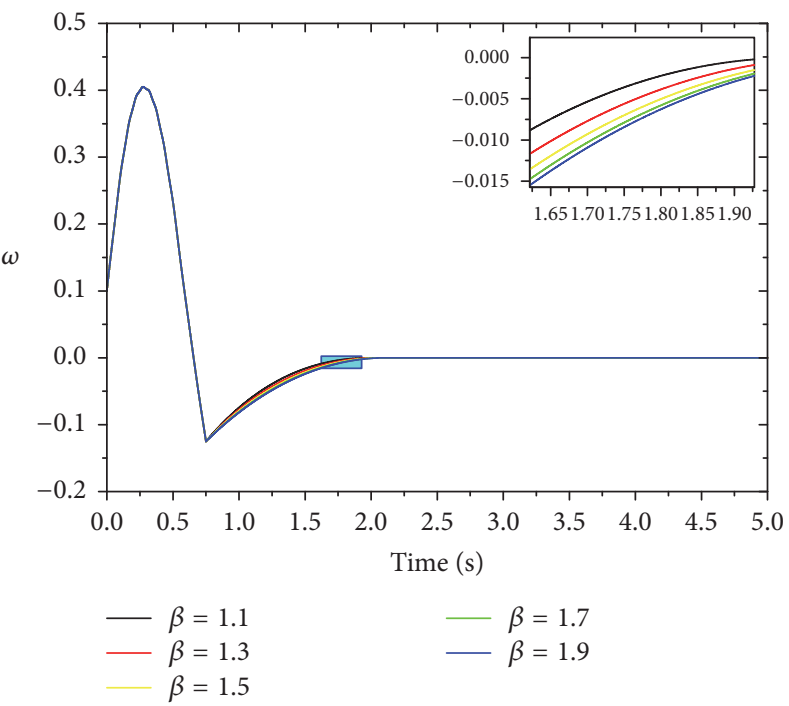

(b)

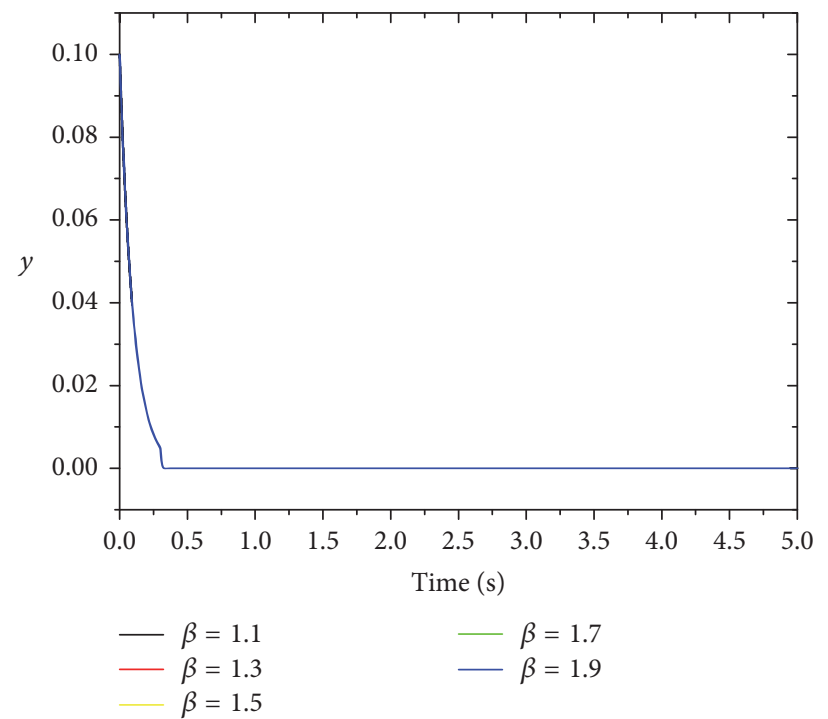

(c)

FIGURE 6: Response of $\beta$ of the system controlled by fixed-time controllers.

at $0.326 \mathrm{~s}$. These simulation results show that when the initial state of the system changes, the settling times of the system state variables have changed, but they are not more than theoretical deduction time $t_{3}$. That is to say, the simulation results are consistent with the theoretical derivation.

\section{Conclusions}

In this paper, to ensure the safe and stable operation of hydraulic turbine governing system, a new control method based on the fixed-time theory is proposed. Compared with the finite-time control method, the hydraulic turbine governing system under the fixed-time controllers has more advantages: better robustness, fast response ability, and the setting time to reach the stable state being regardless of the initial state. Finally, the effectiveness and superiority of the proposed control method are verified by the simulation results. Note that time delay may influence the dynamic behavior of the system; the fixed-time control of hydraulic turbine governing system with time delay is our future direction.

\section{Conflicts of Interest}

The authors declare no conflicts of interest regarding the publication of this paper.

\section{Authors' Contributions}

Caoyuan Ma, Yongzheng Sun, and Chuangzhen Liu conceived and designed the experiments; Chuangzhen Liu, Xuezi Zhang, Wenbei $\mathrm{Wu}$, and Jin Xie performed the experiments 

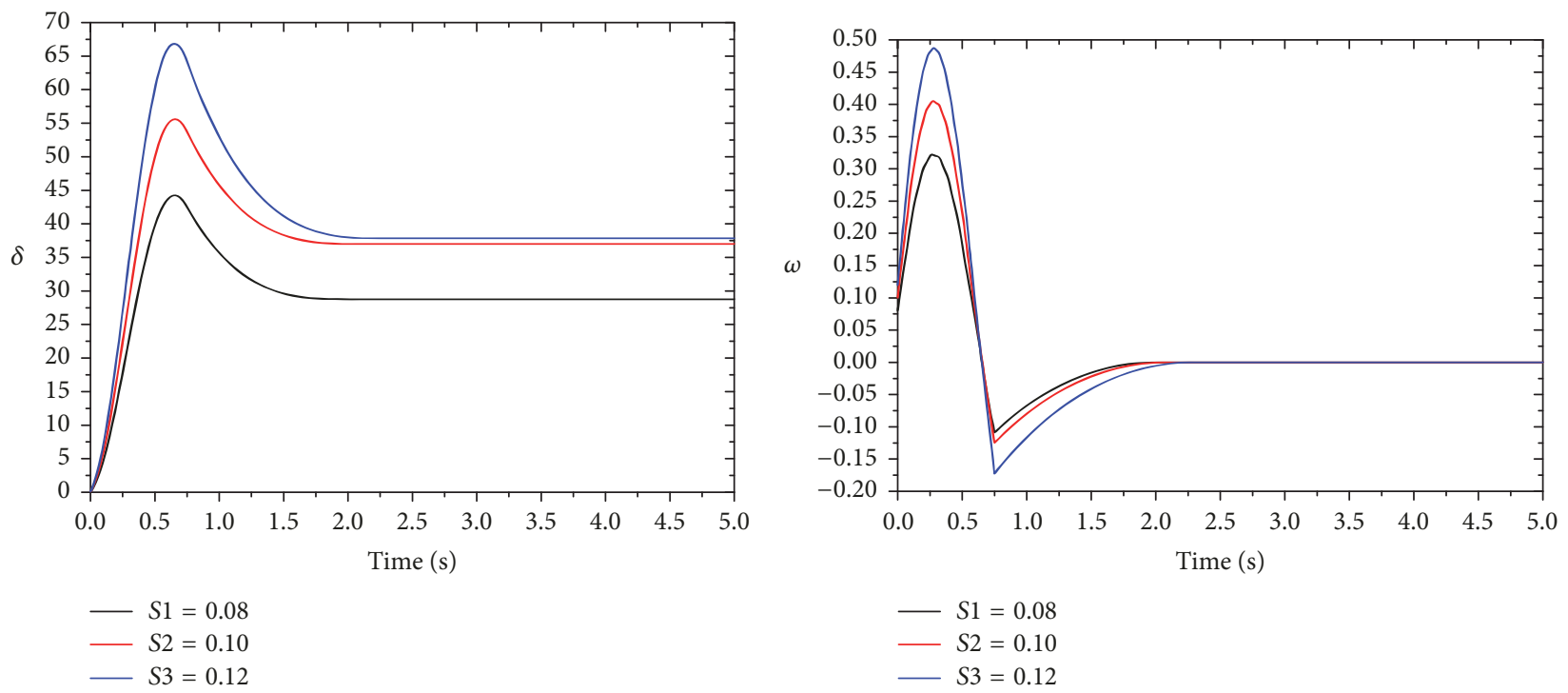

(a)

(b)

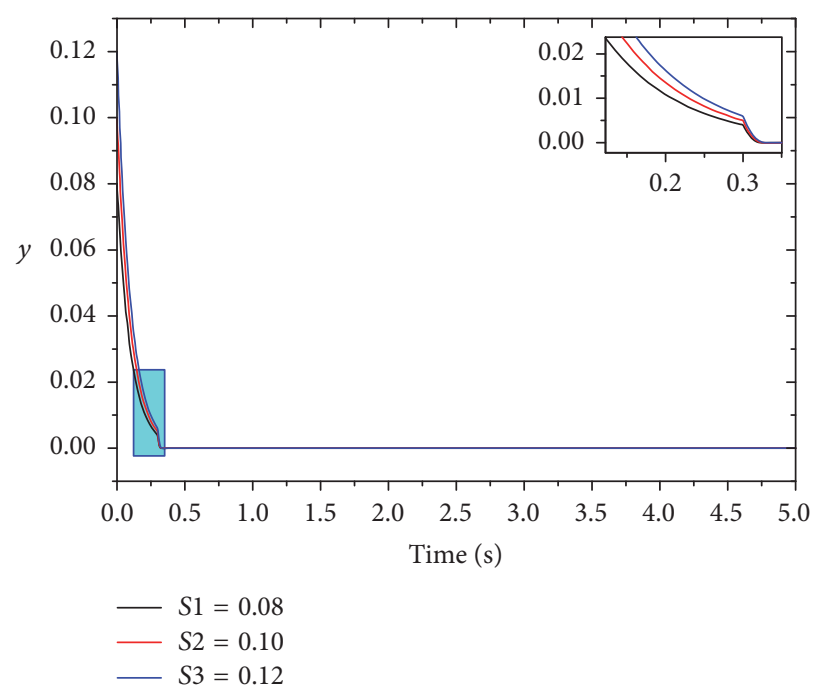

(c)

FIgURE 7: The response of the system with the different $S$.

and analyzed the data; Chuangzhen Liu and Xuezi Zhang wrote the paper.

\section{Acknowledgments}

This work is supported by the Fundamental Research Funds for the Central Universities (Grant no. 2017XKZD11).

\section{References}

[1] R. E. Grumbine and J. Xu, "Mekong hydropower development," Science, vol. 332, no. 6026, pp. 178-179, 2011

[2] B. Xu, D. Chen, H. Zhang, F. Wang, X. Zhang, and Y. Wu, "Hamiltonian model and dynamic analyses for a hydro-turbine governing system with fractional item and time-lag," Communications in Nonlinear Science and Numerical Simulation, vol. 47, pp. 35-47, 2017.
[3] D. J. Ling and Y. Tao, "An analysis of the Hopf bifurcation in a hydroturbine governing system with saturation," IEEE Transactions on Energy Conversion, vol. 21, no. 2, pp. 512-515, 2006.

[4] H. Mesnage, M. Alamir, N. Perrissin-Fabert, and Q. Alloin, "Nonlinear model-based control for minimum-time start of hydraulic turbines," European Journal of Control, vol. 34, pp. 2430, 2017.

[5] W. C. Guo, J. D. Yang, M. J. Wang, and X. Lai, "Nonlinear modeling and stability analysis of hydro-turbine governing system with sloping ceiling tailrace tunnel under load disturbance," Energy Conversion and Management, vol. 106, pp. 127-138, 2015.

[6] D. Chen, C. Ding, Y. Do, X. Ma, H. Zhao, and Y. Wang, "Nonlinear dynamic analysis for a Francis hydro-turbine governing system and its control," Journal of The Franklin Institute, vol. 351, no. 9, pp. 4596-4618, 2014. 
[7] H. H. Li, D. Y. Chen, H. Zhang, F. Wang, and D. Ba, "Nonlinear modeling and dynamic analysis of a hydro-turbine governing system in the process of sudden load increase transient," Mechanical Systems and Signal Processing, vol. 80, pp. 414-428, 2016.

[8] C. Xu and D. Qian, "Governor design for a hydropower plant with an upstream surge tank by GA-based Fuzzy reduced-order sliding mode," Energies, vol. 8, no. 12, pp. 13442-13457, 2015.

[9] X. Yuan, Z. Chen, Y. Yuan, and Y. Huang, "Design of fuzzy sliding mode controller for hydraulic turbine regulating system via input state feedback linearization method," Energy, vol. 93, pp. 173-187, 2015.

[10] X. Yuan, Z. Chen, Y. Yuan, Y. Huang, X. Li, and W. Li, "Sliding mode controller of hydraulic generator regulating system based on the input/output feedback linearization method," Mathematics and Computers in Simulation, vol. 119, pp. 18-34, 2016.

[11] C. Li, N. Zhang, X. Lai, J. Zhou, and Y. Xu, "Design of a fractional-order PID controller for a pumped storage unit using a gravitational search algorithm based on the Cauchy and Gaussian mutation," Information Sciences, vol. 396, pp. 162-181, 2017.

[12] Y. Xu, J. Zhou, X. Xue, W. Fu, W. Zhu, and C. Li, "An adaptively fast fuzzy fractional order PID control for pumped storage hydro unit using improved gravitational search algorithm," Energy Conversion and Management, vol. 111, pp. 67-78, 2016.

[13] C. Li, Y. Mao, J. Zhou, N. Zhang, and X. An, "Design of a fuzzyPID controller for a nonlinear hydraulic turbine governing system by using a novel gravitational search algorithm based on Cauchy mutation and mass weighting," Applied Soft Computing, vol. 52, pp. 290-305, 2017.

[14] S. Simani, S. Alvisi, and M. Venturini, "Data-driven design of a fault tolerant fuzzy controller for a simulated hydroelectric system," IFAC-PapersOnLine, vol. 28, no. 21, pp. 1090-1095, 2015.

[15] S. Simani, S. Alvisi, and M. Venturini, "Fault tolerant control of a simulated hydroelectric system," Control Engineering Practice, vol. 51, pp. 13-25, 2016.

[16] R. Zhang, D. Chen, and X. Ma, "Nonlinear predictive control of a hydropower system model," Entropy, vol. 17, no. 9, pp. 61296149, 2015.

[17] Z. Xiao, S. Meng, N. Lu, and O. P. Malik, "One-Step-Ahead Predictive Control for Hydroturbine Governor," Mathematical Problems in Engineering, vol. 2015, Article ID 382954, 2015.

[18] B. Wang, L. Yin, S. Wang, S. Miao, T. Du, and C. Zuo, "Finite time control for fractional order nonlinear hydroturbine governing system via frequency distributed model," Advances in Mathematical Physics, vol. 2016, Article ID 7345325, 2016.

[19] A. Polyakov, "Nonlinear feedback design for fixed-time stabilization of linear control systems," Institute of Electrical and Electronics Engineers Transactions on Automatic Control, vol. 57, no. 8, pp. 2106-2110, 2012.

[20] Y. Sun and W. Lin, "A positive role of multiplicative noise on the emergence of flocking in a stochastic Cucker-Smale system," Chaos: An Interdisciplinary Journal of Nonlinear Science, vol. 25, no. 8, Article ID 083118, 2015.

[21] Y. Z. Sun, S. Y. Leng, Y. C. Lai, C. Grebogi, and W. Lin, "Closedloop control of complex networks: a trade-off between time and energy," Physical Review Letters, vol. 119, no. 19, Article ID 198301, 2017.

[22] Y. Sun, X. Wu, L. Bai, Z. Wei, and G. Sun, "Finite-time synchronization control and parameter identification of uncertain permanent magnet synchronous motor," Neurocomputing, 2015.
[23] J. Huang, C. Li, T. Huang, and X. He, "Finite-time lag synchronization of delayed neural networks," Neurocomputing, vol. 139, pp. 145-149, 2014.

[24] J. Wu, Z.-c. Ma, Y.-z. Sun, and F. Liu, "Finite-time synchronization of chaotic systems with noise perturbation," Kybernetika, vol. 51, no. 1, pp. 137-149, 2015.

[25] H. F. Hong, W. W. Yu, G. H. Wen, and X. H. Yu, "Distributed robust fixed-time consensus for nonlinear and disturbed multiagent systems," IEEE Transactions on Systems, Man, and Cybernetics: Systems, vol. 47, no. 7, pp. 1464-1473, 2017.

[26] J. Gao and Y. Cai, "Fixed-time control for spacecraft attitude tracking based on quaternion," Acta Astronautica, vol. 115, article no. 5463, pp. 303-313, 2015.

[27] Y. N. Yang, C. C. Hua, J. P. Li, and X. P. Guan, "Fixedtime coordination control for bilateral telerobotics system with asymmetric time-varying delays," Journal of Intelligent Robotic Systems, vol. 86, no. 3-4, pp. 447-466, 2017.

[28] X. Ding, J. Cao, A. Alsaedi, F. E. Alsaadi, and T. Hayat, "Robust fixed-time synchronization for uncertain complex-valued neural networks with discontinuous activation functions," Neural Networks, vol. 90, pp. 42-55, 2017.

[29] C. Hu, J. Yu, Z. Chen, H. Jiang, and T. Huang, "Fixed-time stability of dynamical systems and fixed-time synchronization of coupled discontinuous neural networks," Neural Networks, vol. 89, pp. 74-83, 2017.

[30] J. D. Cao and R. X. Li, "Fixed-time synchronization of delayed memristor-based recurrent neural networks," Science China Information Sciences, vol. 60, no. 3, Article ID 032201, 2017.

[31] Y. Wan, J. Cao, G. Wen, and W. Yu, "Robust fixed-time synchronization of delayed Cohen-Grossberg neural networks," Neural Networks, vol. 73, pp. 86-94, 2016.

[32] J. Ni, L. Liu, C. Liu, X. Hu, and S. Li, "Fast fixed-time nonsingular terminal sliding mode control and its application to chaos suppression in power system," IEEE Transactions on Circuits and Systems II: Express Briefs, vol. 64, no. 2, pp. 151-155, 2017.

[33] J. Ni, L. Liu, C. Liu, X. Hu, and T. Shen, "Fixed-time dynamic surface high-order sliding mode control for chaotic oscillation in power system," Nonlinear Dynamics, vol. 86, no. 1, pp. 401420, 2016.

[34] S. P. Bhat and D. S. Bernstein, "Finite-time stability of continuous autonomous systems," SIAM Journal on Control and Optimization, vol. 38, no. 3, pp. 751-766, 2000.

[35] H. K. Khalil, and J.W.Grizzle, Nonlinear systems third edition, Prentice Hall, Upper Saddle River, 2002. 


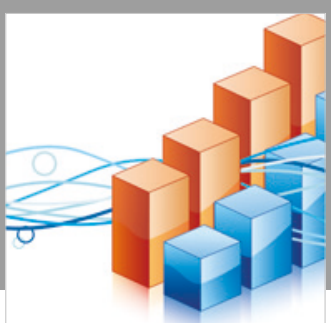

Advances in

Operations Research

\section{-n-m}
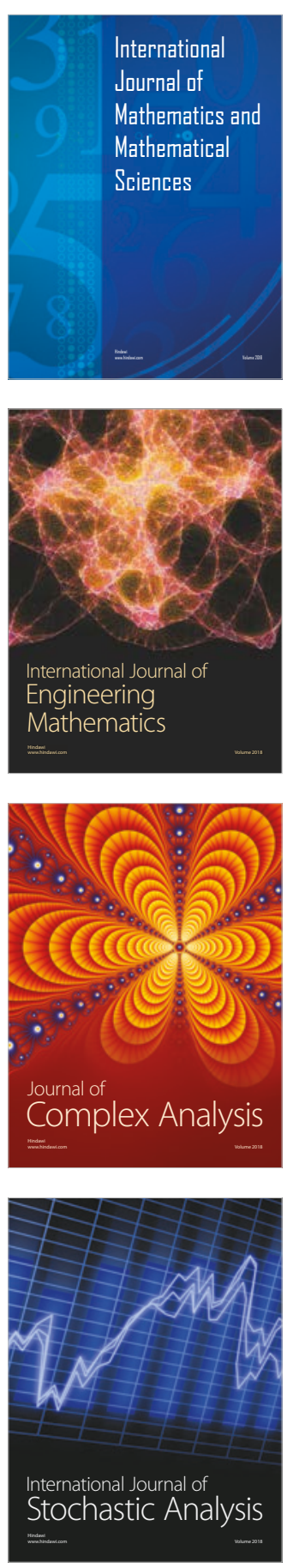
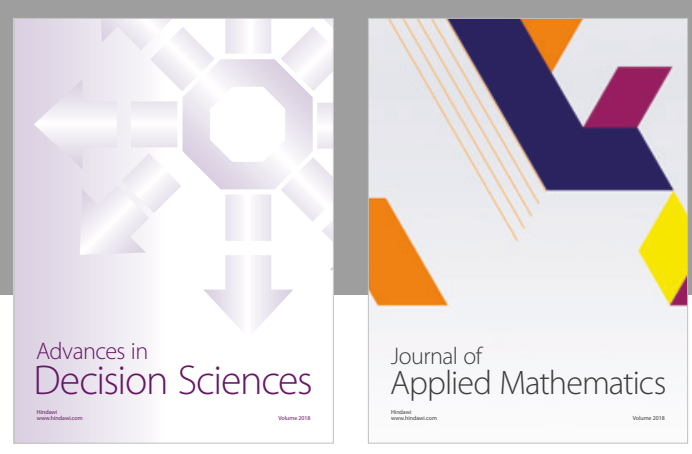

Journal of

Applied Mathematics
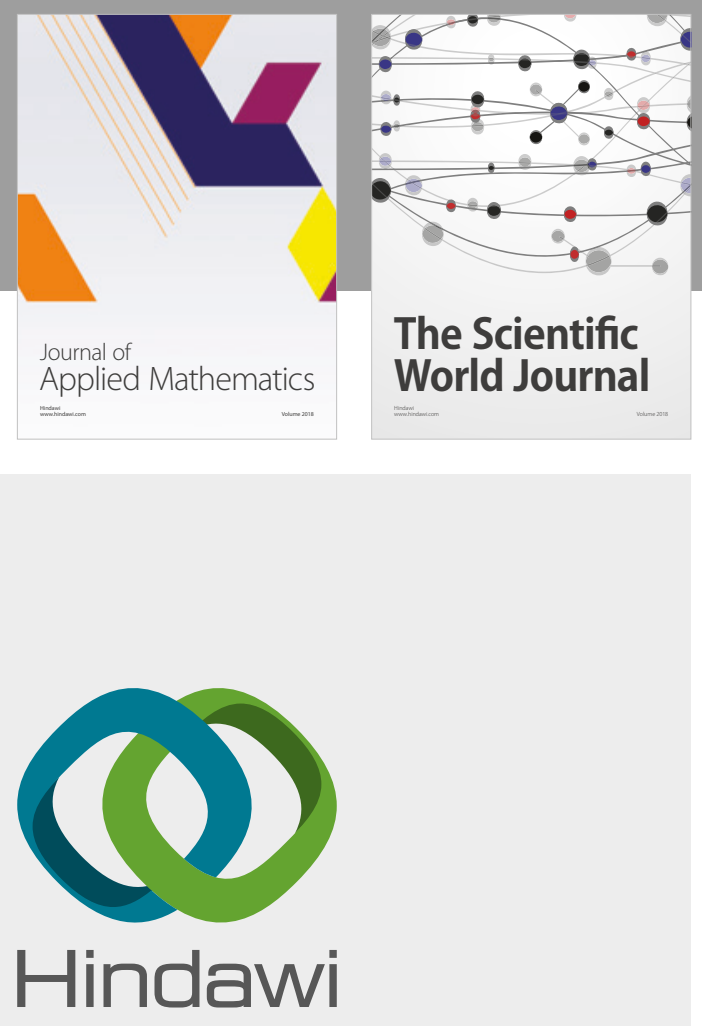

Submit your manuscripts at

www.hindawi.com

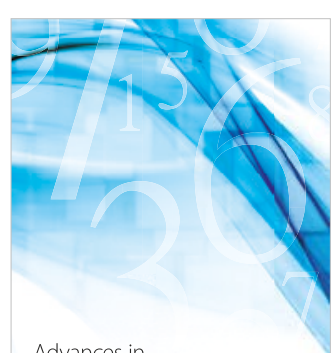

Advances in
Numerical Analysis
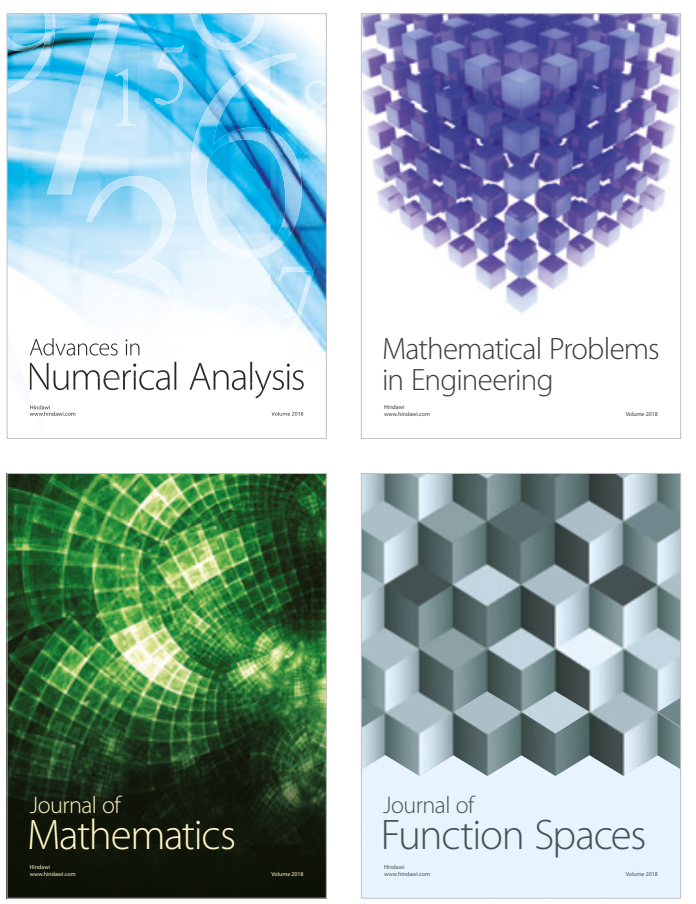

Mathematical Problems in Engineering

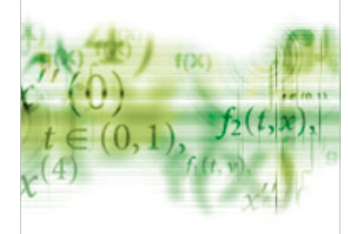

International Journal of

Differential Equations

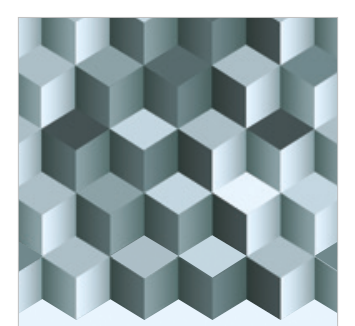

Journal of

Function Spaces

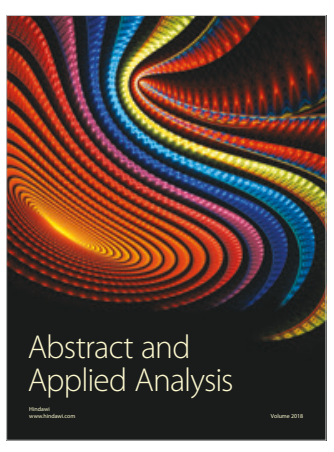

The Scientific

World Journal

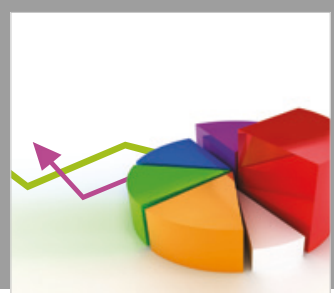

Journal of

Probability and Statistics
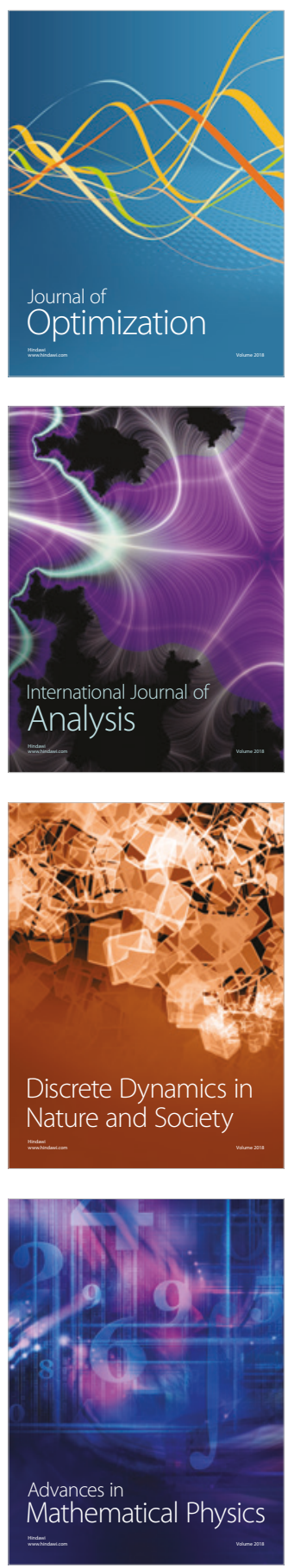